\title{
Mechanical Behaviour and Fracture Mechanics of Praseodymium Modified Lead Titanate Ceramics Prepared by Solid-State Reaction Route
}

\author{
Vishal Singh, Shivani Suri, and K. K. Bamzai \\ Crystal Growth \& Materials Research Laboratory, Department of Physics and Electronics, University of Jammu, Jammu 180006, India \\ Correspondence should be addressed to K. K. Bamzai; kkbamz@yahoo.com
}

Received 27 December 2012; Accepted 25 July 2013

Academic Editor: Zhenxing Yue

Copyright ( 2013 Vishal Singh et al. This is an open access article distributed under the Creative Commons Attribution License, which permits unrestricted use, distribution, and reproduction in any medium, provided the original work is properly cited.

\begin{abstract}
The praseodymium modified lead titanate ceramics with composition $\mathrm{Pb}_{1-x} \mathrm{Pr}_{x} \mathrm{Ti}_{0.96} \mathrm{Fe}_{0.02} \mathrm{Mo}_{0.02} \mathrm{O}_{3}$ where $x=0.04,0.06,0.08$, and 0.10 prepared by solid-state reaction technique were subjected to indentation induced hardness testing method. The indentations were induced in the applied load ranging from $0.245 \mathrm{~N}$ to $4.90 \mathrm{~N}$. The microhardness varies nonlinearly with load and was best explained by the concept of Newtonian resistance pressure as proposed by Hays and Kendall's law. Crack propagation, fracture toughness $\left(K_{c}\right)$, brittleness index $\left(B_{i}\right)$, and yield strength $\left(\sigma_{y}\right)$ were studied to understand the effect of Pr content on various mechanical parameters. The load independent values were found to increase with the increase in praseodymium content.
\end{abstract}

\section{Introduction}

Ceramics are generally associated with distinctive problems, some uniquely beneficial and restrictive which determine the materials utilities, among these are hardness, brittleness, and fracture toughness. The measured hardness of a brittle material as determined by conventional tests (Vickers, Knoop, Rockwell, etc.) is a measure of materials resistance to deformation, densification, displacement and fracture. Conventional hardness measurements, which depend on size of an indentation resulting from an applied load, are load independent. This is especially noticeable at lower indentation loads where most measurements are made in order to avoid experimental problems associated with fracture. Local fracture around and under an indentation can affect the depth of penetration or size of the indentation and thus can be considered an intrinsic part of the indentation process. Fracture can also create practical difficulties in making hardness measurements because cracking at indentation corners or fragmentation can hamper hardness measurements. The degree of fracture at indentations in ceramics is load dependent. Low loads are associated with deformation while fracture is conspicuously more prominent at high loads. Microindentation technology has been used for the measurements of fracture toughness of ceramic materials by Evans and Charles [1]. Generally, the dielectric, piezoelectric, elastic, and mechanical behavior of ferroelectric ceramics depend in a complex way on microstructural parameters such as porosity, grain size, and grain boundary effects. The properties of ferroelectric ceramics are also very sensitive to temperature, to stress and strain, to frequency, and so forth.

Lead titanate $\left(\mathrm{PbTiO}_{3}\right)$ is well known as a perovskites type ferroelectric material with a high Curie point $\left(T_{c}\right)$ of $490^{\circ} \mathrm{C}$. A phase transition from the paraelectric cubic phase to the ferroelectric tetragonal phase takes place on decreasing the temperature through the Curie point. Lead titanate (PT) is very difficult to fabricate in the bulk form as they undergo a large volume change on cooling below the Curie point. It is a result of cubic $(c / a=1.00)$ to tetragonal $(c / a=1.064)$ phase transformation leading to a strain. Evidence for the existence of internal stress is the observation that sintered pure PT ceramic gradually disintegrates into powder at room temperature due to mechanical breakdown [2]. Therefore, dense PT ceramics were prepared by adding suitable additives or combining with other compounds to form solid solution $[3,4]$. The modified PT ceramics are material of interest due to the piezoelectric properties which is due to spontaneous polarization. However, their poor mechanical performance, 
TABLE 1: Lattice constants $(a, c)$, X-ray density, experimental density, relative density, and porosity for different composition of Pr substituted in lead titanate.

\begin{tabular}{|c|c|c|c|c|c|c|}
\hline$x$ & $a(\AA)$ & $c(\AA)$ & $\rho_{\mathrm{X}-\operatorname{ray}(\mathrm{g} / \mathrm{cc})}$ & $\rho_{\mathrm{ex}(\mathrm{g} / \mathrm{cc})}$ & Relative density (\%) & Porosity \\
\hline 0.02 & 3.94 & 4.15 & 7.80 & 7.25 & 92.94 & 7.05 \\
\hline 0.04 & 3.88 & 4.04 & 8.23 & 7.65 & 92.95 & 7.04 \\
\hline 0.06 & 3.91 & 4.05 & 8.07 & 7.51 & 93.06 & 6.93 \\
\hline 0.08 & 3.90 & 4.02 & 8.11 & 7.58 & 93.46 & 6.53 \\
\hline 0.10 & 3.81 & 3.99 & 8.18 & 7.74 & 94.62 & 5.36 \\
\hline
\end{tabular}

that is, low bonding strength and low fracture toughness, limits their applications in the field where high strength and high fracture toughness are the important requirement. The piezoelectric, and mechanical properties in modified PT ceramics are important for the use in the generation of high power ultrasonic [1]. The mechanical characteristics of modified PT ceramics are as important as the dielectric, piezoelectric and ferroelectric characteristics. Hence, more and more attention has been focused on understanding and improving the mechanical properties of PT ceramics. This paper reports in a systematic manner, the mechanical characterization of Pr modified lead titanate ceramics using Vickers indentation technique. The relationship between hardness, fracture toughness, brittleness index, yield strength, and their dependence on microstructure and load is also studied. To the best of the author's knowledge, there is no such report on the Pr modified lead titanate ceramics.

\section{Materials and Methods}

Praseodymium modified lead titanate (PrPT) ceramics with composition $\mathrm{Pb}_{1-x} \mathrm{Pr}_{x} \mathrm{Ti}_{0.96} \mathrm{Fe}_{0.02} \mathrm{Mo}_{0.02} \mathrm{O}_{3}$ where $x=0.04$, $0.06,0.08$, and 0.10 were prepared by solid-state reaction technique. The prepared samples were sintered at temperature $1100^{\circ} \mathrm{C}$ for $2 \mathrm{~h}$. The lattice parameters were calculated using X-ray diffraction pattern whereas microstructural characterization was carried out using electron microscopy, and grain size was measured using the line intercept method, the detail of which has already been reported [5]. In order to study the mechanical characterization, the synthesized material was first of all smoothened by grinding with fine alumina abrasive powder in aqueous medium. To have good reflectivity, necessary for observation under a microscope, the material was then polished with diamond paste on a rotatory polishing machine. Praseodymium modified lead titanate disks of about $10-12 \mathrm{~mm}$ in diameter and $2 \mathrm{~mm}$ in thickness with optically finished surfaces were used for Vickers microhardness analysis. In the present study, indentation induced microhardness was carried in the load range of $0.245 \mathrm{~N}$ to $4.903 \mathrm{~N}$, keeping the indenter at right angles to the surface for 10 seconds in all cases, irrespective of the load. The instrument used is "Auto Detection Microhardness Analyzer" "HMV-2" of Shimadzu, Japan. At least five indentations were made on each composition for each load. The distance between any two indentations was kept more than five times the diagonal length of the indentation mark, so as to ensure that surface effects are independent of each other. The diagonal length of each indentation impression was measured, and average diagonal length was computed for calculation. Microhardness was calculated using the formula

$$
H_{v}=2 \sin 68^{\circ} \frac{P}{d^{2}}=1.8544 \frac{P}{d^{2}} \mathrm{Nm}^{-2},
$$

where " $P$ " is the applied load and " $d$ " the diagonal length of the indentation mark in micrometers. The error on " $H_{v}$ " is estimated through the relation:

$$
\Delta H_{v}=1.8544\left[\left(\frac{\Delta P}{Y}\right)^{2}+\left(\frac{P \Delta Y}{Y^{2}}\right)\right]^{1 / 2},
$$

where $Y=d^{2}$ and $\Delta Y=2 d \Delta d ; \Delta P, \Delta Y$ and $\Delta d$ denote errors of $P, Y$, and $d$, respectively.

For each measurement, only well-defined cracks developed during indentation were considered for a particular indentation impression. The crack length was measured from the centre of indentation mark up to the tip of the crack. A program in Fortran 77, using the method of least squares, was made and run on computer to calculate the values of various parameters.

\section{Results and Discussion}

3.1. Crystal Tetragonality. X-ray diffraction analysis was used for the identification and crystal system of the different compositions of PrPT ceramics. Figure 1 is the $\mathrm{X}$-ray diffraction analysis of different $\mathrm{PrPT}$ compositions showing single phase tetragonal structure as per JCPDS data no. 06-452, whereas Figure 2 shows variation of lattice constants $(a, c)$ and crystal tetragonality $(c / a)$ with various $\operatorname{Pr}$ substitutions. The increase in Pr content decreases the crystal tetragonality $(c / a)$, and it was observed that $c / a$ ratio is always less than 1.064 (the value of pure $\mathrm{PbTiO}_{3}$ ceramics). The decrease in the tetragonality with the increase in Pr content clearly indicates that Pr ions enter the lattice on $\mathrm{A}$-site replacing $\mathrm{Pb}$ ions resulting in the formation of hard and dense ceramics. A compiled data of lattice constants $(a, c), \mathrm{X}$-ray density, experimental density, relative density, and porosity for different composition of Pr substituted in lead titanate is shown in Table 1. It was found that relative density increases from $92.94 \%$ to $94.62 \%$ of the theoretical density with the increase in praseodymium content. The increase in experimental densities and reduction in porosity is due to the fact that increase in Pr content decreases the tetragonality in PT ceramic, because of its large spontaneous stress described as $(T s \alpha(c / a-1))$ [6]. Reduction in internal stress allows the crystallites in grains to 


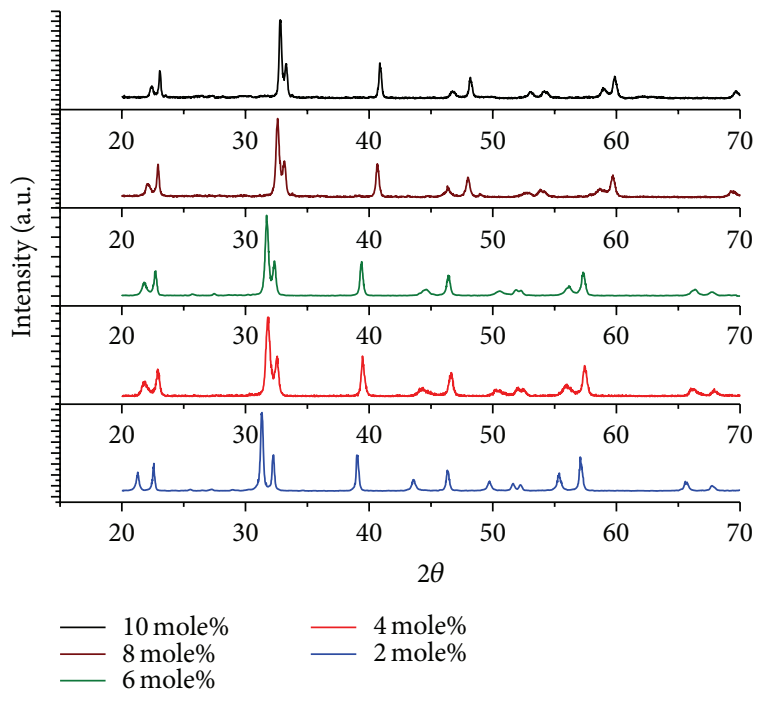

FIGURE 1: Compiled XRD pattern of 2, 4, 6, 8, and 10 mole\% of Pr modified lead titanate.

accommodate more closely to form a denser microstructure, which results in reduction in porosity and increase in density. From the X-ray diffraction pattern, it has been found that as the amount of Pr increases, the main peak 101 shifts towards higher angle as clearly seen in Figure 3, which indicates a decrease in lattice constant [7]. Figure 4 shows one of the representative scanning electron microscopic image with their three-dimension view for 8 mole\% of PrPT compositions. From the photomicrograph and its three-dimension view, one can clearly observe the uniform distribution of the grain in the prepared material, and the grain size varies with compositions and ranges from 268 to $531 \mathrm{~nm}$ [5].

3.2. Mechanical Behavior. The dependence of microhardness on the applied load shows different behaviour for different materials. The microhardness is reported to be (i) independent of load [8], (ii) is a function of load $[9,10]$, and shows complex behavior with change of applied load [11,12]. The results of indentation induced microhardness studies on PrPT ceramics reveal that microhardness value $\left(H_{v}\right)$ decreases nonlinearly as the applied load increases from $0.245 \mathrm{~N}$ to $1.961 \mathrm{~N}$ in all compositions, and thereafter, the values tend to attain saturation. For 4 mole $\%$ of PrPT, the microhardness values ranges from 7239 to $5833 \mathrm{MNm}^{-2}$ in the load ranging from 0.245 to $4.903 \mathrm{~N}$. The hardness value increases with compositions for each applied load, and for 10 mole $\%$ of PrPT, the value comes out to be in the range $14486-11604 \mathrm{MNm}^{-2}$ in the load range of $0.245-4.903 \mathrm{~N}$. The behaviour of Vickers microhardness $\left(H_{y}\right)$ with applied load for the four different compositions of PrPT is shown in Figure 5. Decrease in microhardness at loads greater than $0.098 \mathrm{~N}$ with a trend to stabilize at higher loads is reported in calcium modified lead titanate ceramics [13]. The decrease in microhardness value can be quantitatively explained on the

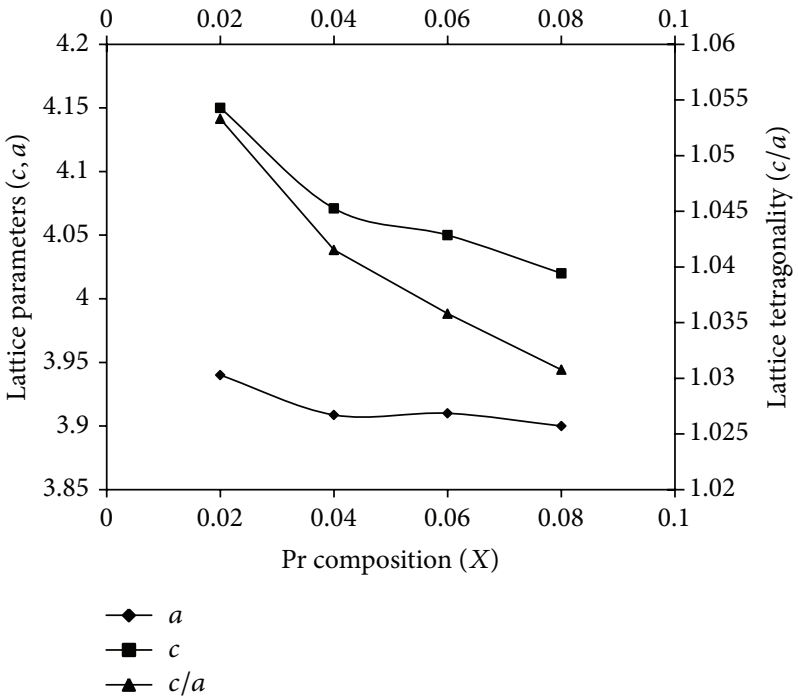

FIGURE 2: Effect of Pr substitution on crystal tetragonality $(c / a)$ and cell parameters $(a, c)$.

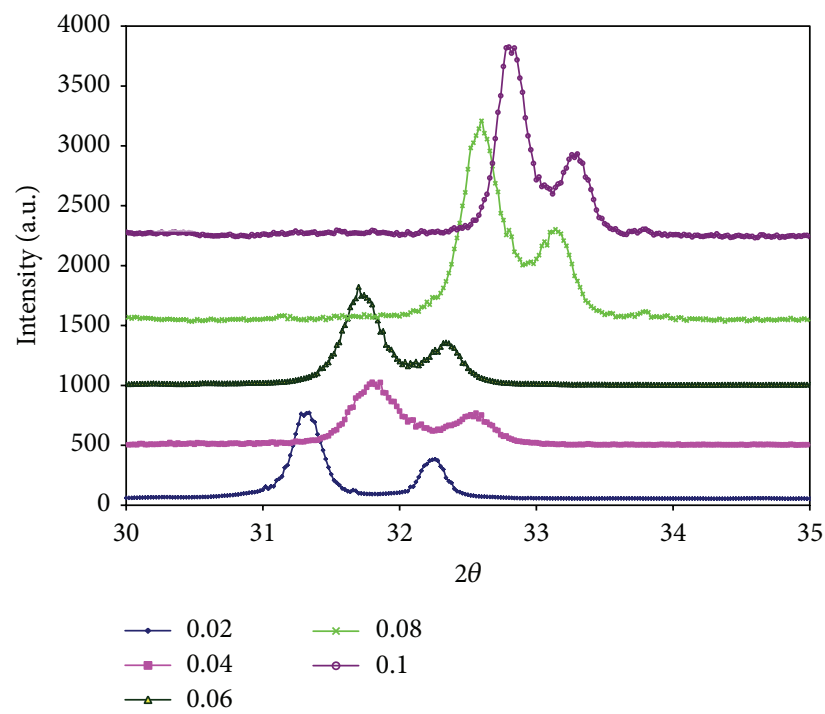

FIGURE 3: XRD pattern showing shift in the main peak [101] towards higher angle for different compositions.

basis of penetration depth of the indentor. Since the indentor penetrates only surface layers at low loads, the effect is more pronounced at these loads. However, as the penetration depth increases, the effect of inner layers becomes more and more prominent, and ultimately there is no change in the value of hardness with load [14, 15]. In the present case, the hardness values get saturated above $1.961 \mathrm{~N}$. This explanation is also favoured by Brookes [16], who associated the hardness increase at low loads with the early stages of plastic deformation. The dependence of hardness with loads in case of different compositions is not in accordance with the Kick's law [17]

$$
P=K_{1} d^{n},
$$



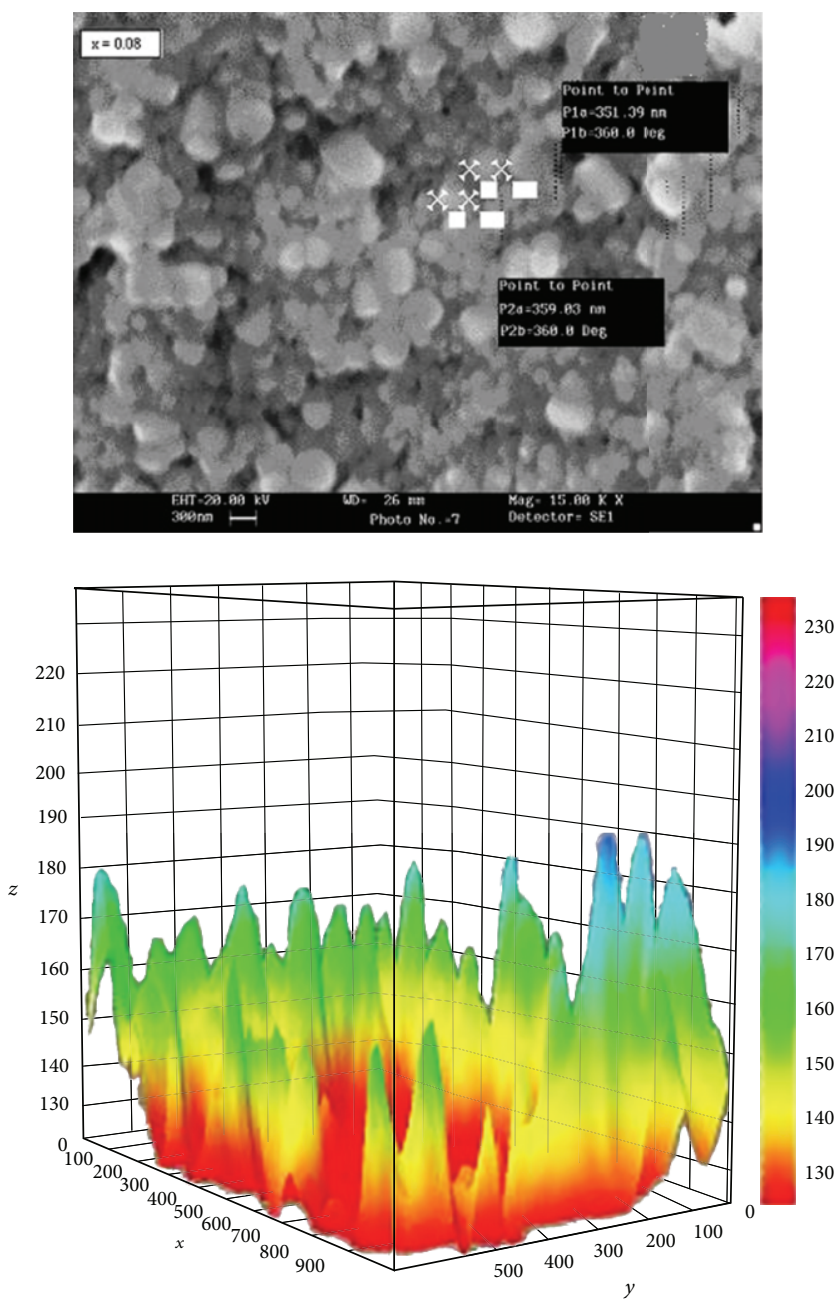

FIGURE 4: Scanning electron micrograph with three-dimension view for 8 mole\% of PrPT composition.

where " $K_{1}$ " is the standard hardness constant and " $n$ " is the Meyer's index (or work hardening coefficient) which is proposed to be equal to 2, implying that the hardness is independent of load. A plot of "log $P$ " versus " $\log d$ " shown in Figure 6, according to (3), using least square fitting method gives the value of " $n$ " and " $K_{1}$," as determined from the slope and intercept, respectively. The value of " $n$ " comes out to be $1.86,1.84,1.86$, and 1.85 for 4,68 , and 10 mol\% compositions, respectively. In each case, the value of $n$ is less than 2 . The value of $n<2$ in the case of those materials where hardness decreases with load [18] which is also consistent with our observations. In the low load region, resistance offered by the material may be comparable with applied load, resulting in higher values of hardness.

Hardness is defined as the ability of a body to resist permanent deformation and is expressed as the ratio of load applied to the area of indentation. This does not necessarily imply that the applied pressure actually acts on the specimen. According to Hays and Kendall's law [19], it is assumed that the applied load " $P$ " is partially affected by small resultant pressure "W", which is a function of material under investigation. " $W$ " is thus the minimum applied load required to cause a plastic deformation. Hays and Kendall [19] modified Kick's law [17] on the basis of sample resistance pressure $(W)$. According to them,

$$
P-W=K_{2} d^{2},
$$

where " $K_{2}$ " is a constant and $n=2$ is the logarithmic index. In this case, $n$ would be equal to 2 , since it is proposed that the factor " $W$ " allows the limiting case to prevail where the hardness is not markedly dependent on the load. To evaluate " $W$," it is feasible to solve (3) and (4) by substituting for $P$ from (3) in (4), so as to get

$$
W=K_{1} d^{n}-K_{2} d^{2}
$$

or

$$
d^{n}=\frac{K_{2}}{K_{1}} * d^{2}+\frac{W}{K_{1}} .
$$

Figure 7 shows a plot of $d^{n}$ versus $d^{2}$ for different compositions of PrPT. The value of $K_{2} / K_{1}$ and $W / K_{1}$ is obtained from the slope and intercept of the plots using least square fitting method. Having obtained the value of " $K_{1}$ " from Figure 6, the value of " $K_{2}$ " and " $W$ " is calculated for the different compositions of PrPT and is given in Table 2. A plot of " $\log (P-W)$ " versus " $\log d$ " shown in Figure 8 yields the value of $n=2$, thereby suggesting the validity of the theory involving concept of resistance pressure $(W)$ as proposed by Hays and Kendall's law.

The application of Hays and Kendall's law lead us to a formula which gives load independent value of $H_{v}$ :

$$
H_{v}=1.8544 \frac{P-W}{d^{2}}
$$

or

$$
H_{v}=1.8544 K_{2} .
$$

Equation (8) gives the microhardness value independent of load. Thus, microhardness value as calculated by using (8) for 4, 6, 8, and 10 mole\% of PrPT comes out to be 6018, 6237, 9704 , and $11566 \mathrm{MN} / \mathrm{m}^{2}$, respectively.

The microhardness value decreases initially as the load increases and tends to attain saturation at loads greater than $1.96 \mathrm{~N}$ and continues to remain saturated up to the maximum applied load of $4.903 \mathrm{~N}$ as seen in Figure 5. The saturated value of " $H_{v}$ " is consistent with the load independent value of " $H_{v}$ " as obtained from (8). The load independent value of hardness is found to increase linearly with praseodymium substitution. Increase in praseodymium substitution reduces lattice tetragonality [20], which results in the formation of hard and dense ceramics. Increase in $H_{v}$ with decreasing tetragonality has been reported for modified lead titanate ceramics [21]. These results attributed to internal stresses induced in the sample on cubic-tetragonal phase transition. Tickoo et al. [22] and Yamamoto et al. [23] have reported decrease of crystal tetragonality as the lanthanum content in 
TABLE 2: Data on microhardness measurements and analysis for various compositions of PrPT ceramics.

\begin{tabular}{lcccc}
\hline Pr composition & $n_{k}{ }^{*}$ & $n_{h}{ }^{* *}$ & $K_{1}\left(\mathrm{GNm}^{-2}\right)$ & $K_{2}\left(\mathrm{GNm}^{-2}\right)$ \\
\hline 4 mole\% & $1.86 \pm 03$ & $1.95 \pm 04$ & 5.3 & 3.2 \\
6 mole\% & $1.84 \pm 03$ & $1.92 \pm 03$ & 5.9 & 3.3 \\
8 mole\% & $1.86 \pm 03$ & $1.95 \pm 03$ & 7.9 & 5.2 \\
10 mole\% & $1.85 \pm 03$ & $1.93 \pm 03$ & 8.7 & 0.067 \\
\hline
\end{tabular}

$n_{k}{ }^{*}$ represents the value of Mayer's index " $n$ " on operation of Kick's law $\left(P=K_{1} d^{n}\right)$.

$n_{h}{ }^{* *}$ represents the value of Mayer's index " $n$ " on operation of Hays and Kendall's law $(P-W)=K_{2} d^{2}$.

Hardness $\left(H_{v}\right)$ versus load $(P)$

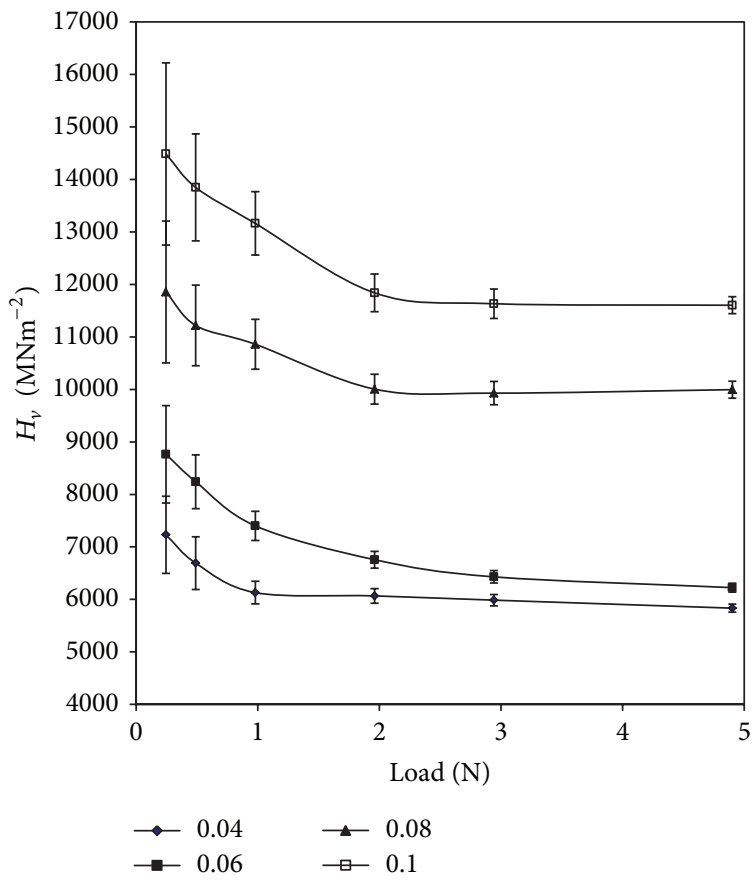

FIGURE 5: Variation of microhardness $\left(H_{V}\right)$ as a function of applied load $(P)$ of $\mathrm{Pb}_{1-x} \mathrm{Pr}_{x} \mathrm{Ti}_{0.96} \mathrm{Fe}_{0.02} \mathrm{Mo}_{0.02} \mathrm{O}_{3}$ ceramics for different compositions $x=0.04,0.06,0.08$, and 0.10 showing nonlinear behavior of system.

PT ceramics increases. They have further observed that the decrease in tetragonality increases Vickers hardness, thereby suggesting that as the praseodymium content increases, the Vickers hardness is expected to increase. It is further supported by the observations made by Okazaki [24].

3.2.1. Yield Strength. From the hardness values, the yield strength " $\sigma_{y}$ ” can be calculated [25]. For Meyer's index $n<2$,

$$
\sigma_{y}=\frac{H_{v}}{3} .
$$

As the values of " $n$ " for each composition of praseodymium modified lead titanate is found to be less than 2, therefore, (9) is applied in the present case. Yield strength for 4 mole\% is found to have values varying from 2410 to $1944 \mathrm{MNm}^{-2}$ for $6 \mathrm{~mole} \%, 2921$ to $2074 \mathrm{MNm}^{-2}$, for $8 \mathrm{~mole} \%, 3952$ to $3331 \mathrm{MNm}^{-2}$, and for $10 \mathrm{~mole} \%$ the value varies from 4828

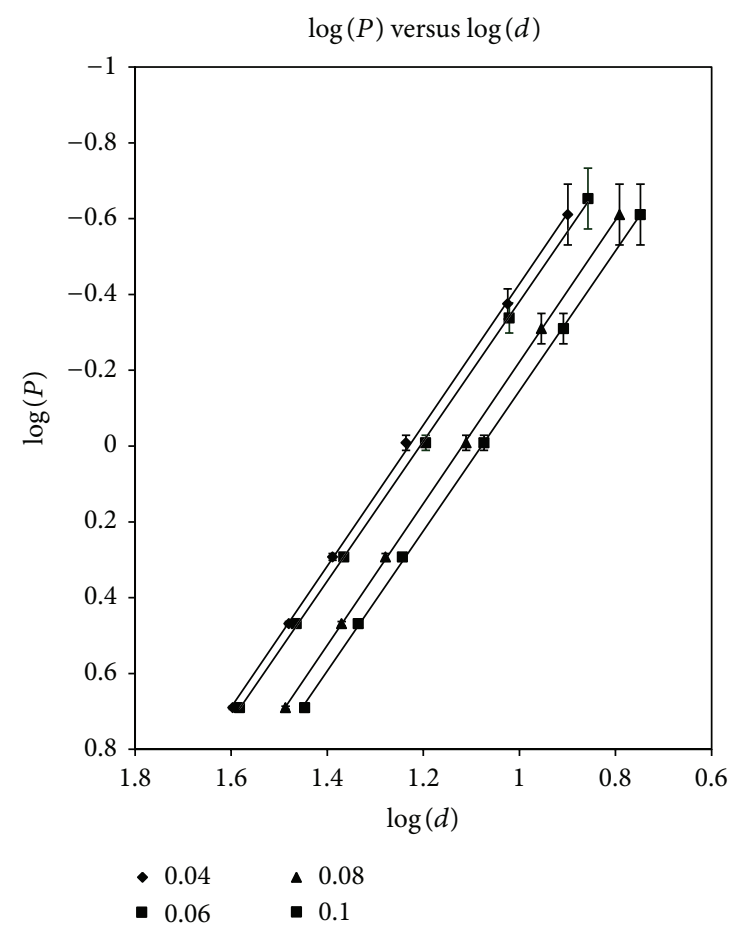

Figure 6: Graph of $\log (P)$ versus $\log (d)$ for different compositions of PrPT.

to $3868 \mathrm{MNm}^{-2}$ under the load range from 0.245 to $4.903 \mathrm{~N}$ respectively.

\subsection{Fracture Mechanics}

3.3.1. Fracture Toughness. Resistance to fracture indicates the toughness of a material. The indentation load for crack initiation reflects the intrinsic deformation and fracture properties of the material $[26,27]$. The crack developed on a crystal determines the fracture toughness " $K_{c}$," which in turn tells us how much fracture stress is applied under uniform loading. The fracture toughness is an important parameter for the selection of materials for application where the load exceeds the limit or yield point. The fracture toughness value depends on the type of crack system and is given by Ponton and Rawlings [28]. Generally, the fracture toughness " $K_{c}$ " measured by microindentation technique is expressed as

$$
K_{c}=\frac{P}{\beta_{0} c^{3 / 2}} \quad \text { For } c \geq \frac{d}{2},
$$


TABLE 3: Data regarding crack length " $c$," half of diagonal length " $a$," value of $c / a$, and nature of cracks.

\begin{tabular}{lcccc}
\hline Applied load $(P)(\mathrm{N})$ & Crack length $(c)(\mu \mathrm{m})$ & Half diagonal length $(a)(\mu \mathrm{m})$ & $c / a$ & Nature of cracks \\
\hline 0.245 & - & 3.09 & - & - \\
0.49 & - & 4.5 & 1.77 & Palmqvist \\
0.98 & 11.45 & 6.45 & 1.87 & Palmqvist \\
1.96 & 117.8 & 9.5 & 1.64 & Palmqvist \\
2.94 & 219.26 & 11.72 & 1.62 & Palmqvist \\
4.903 & 24.86 & 15.33 & & \\
\hline
\end{tabular}

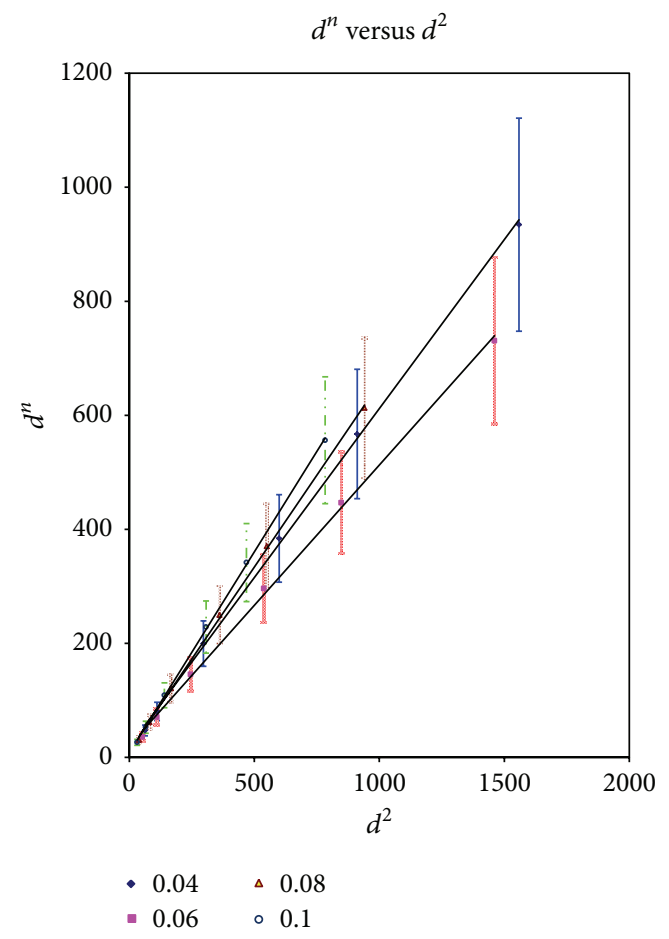

FIGURE 7: Graph showing $d^{n}$ versus $d^{2}$ curve for PrPT ceramics.

where " $P$ " is the applied load in Newton, " $c$ " is the crack length measured from the center of indentation mark to crack end (in $\mu \mathrm{m}$ ), and " $\beta_{0}$ " is the numerical constant that depends upon the indenter geometry. For a Vickers indenter, " $\beta_{0}$ " is equal to 7 . However, the analysis based on (10) yields reliable values of the fracture toughness only if $c / a \geq 2.5$; that is, when the crack system is median or half-penny, where " $a$ " is the length of the half-diagonal of the indent. For $c / a<2.5$ (when crack system is Palmqvist type), the values of " $K_{c}$ " appear less satisfactory $[29,30]$. The fracture toughness values for Palmqvist type of crack system may be calculated by generalized Palmqvist equation $[28,30]$ as

$$
K_{c}=\frac{P}{\beta_{0} a l^{1 / 2}},
$$

where $l=c-a$ is the mean Palmqvist crack length.

In the present studies, it was observed that the cracks become prominent and measurable at applied load of $0.98 \mathrm{~N}$

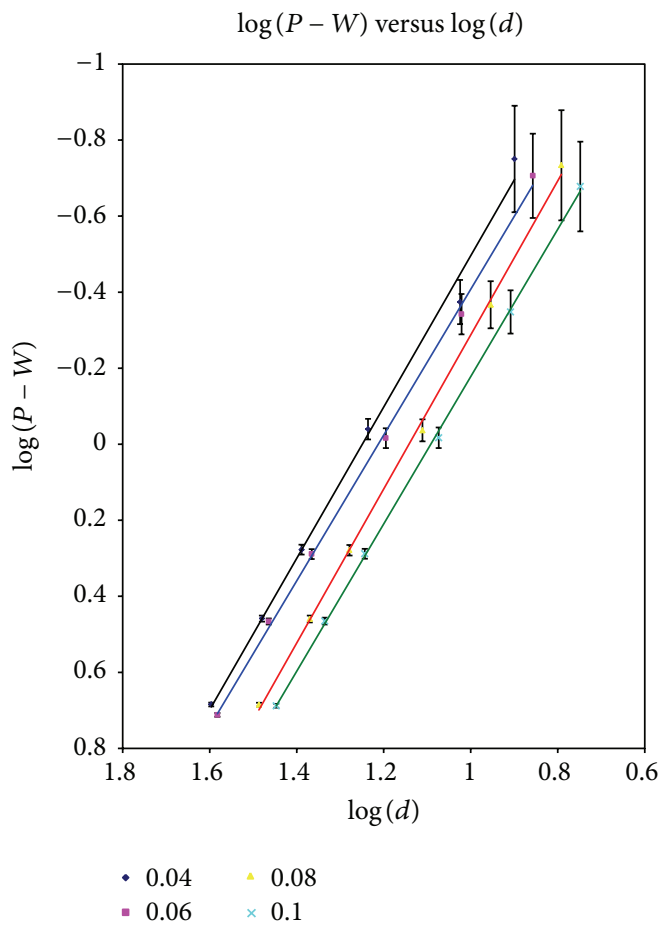

Figure 8: A graph of $\log (P-W)$ with $\log (d)$ showing straight line for different compositions of PrPT.

and above. Figure 9 shows the representative photomicrograph of indentation marks and cracks associated with them at an applied load of $1.961 \mathrm{~N}$ for all the four compositions of Pr modified lead titanate. The crack length increases as the applied load increases for 4, 6, 8, and 10 mole\% and is shown in Figure 10, but it is also observed that crack length at a particular load decreases with the increase in $\mathrm{Pr}$ substitution which indicates the dependence of crack length on both the applied load and variation of Pr substitution. All the cracks developed in the load ranges from 0.980 to $4.903 \mathrm{~N}$ are Palmqvist in nature as in all composition the value of $c / a$ is less than 2.5. Table 3 gives a compiled data regarding the crack length, value of $c / a$, and nature of cracks associated with the corresponding load. Fracture toughness " $K_{c}$ " is calculated using (11) and its dependence on applied load for different compositions is shown in Figure 11. Fracture toughness increases with the increase in load and tends to attain saturation at higher loads. Also fracture toughness at a given load is found to increase with the increase in praseodymium substitution. 

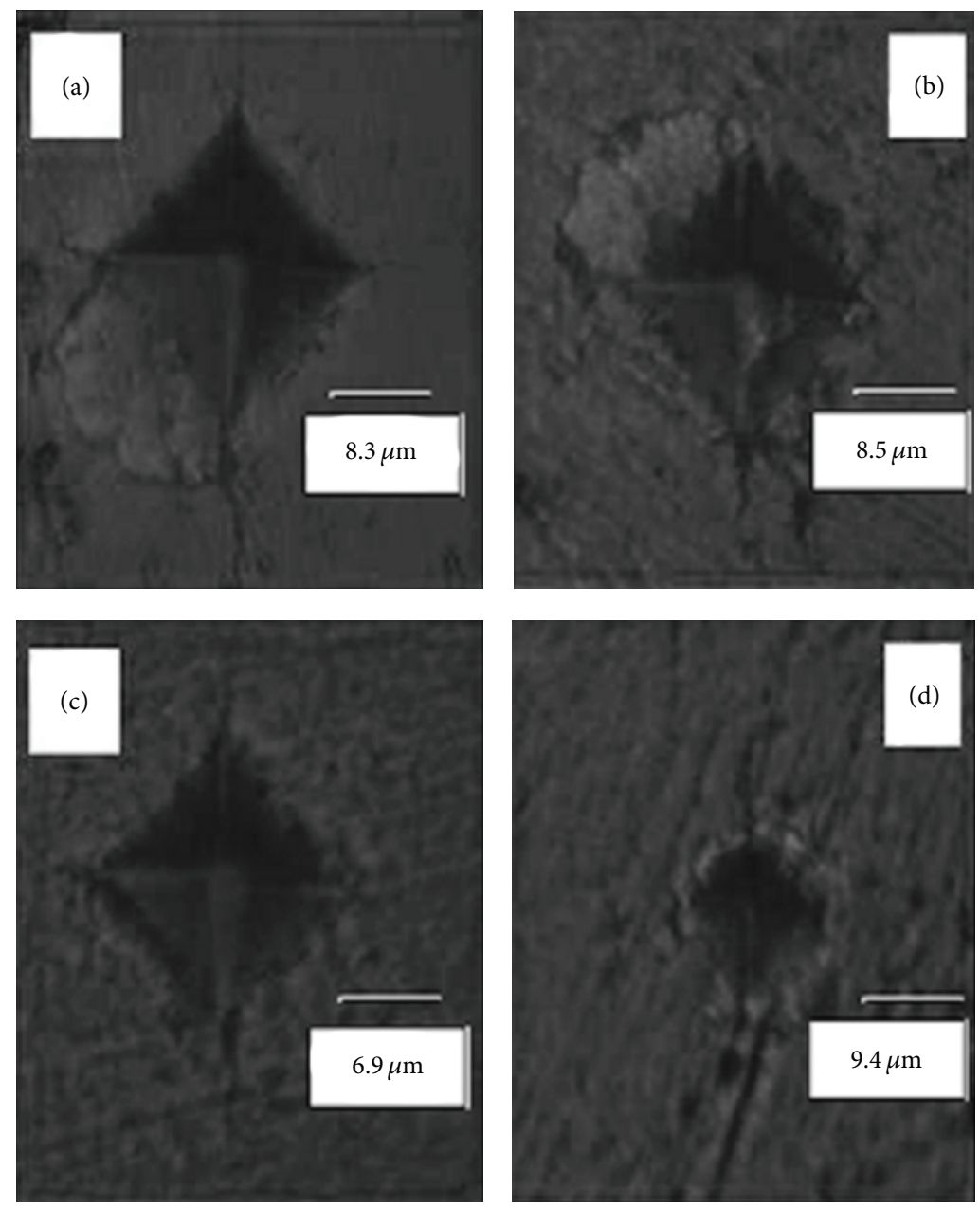

Figure 9: Micrograph showing indentation marks and associated cracks at $1.961 \mathrm{~N}$ of the applied load: (a) 4 mole $\%$, (b) 6 mole $\%$, (c) 8 mole\%, and (d) 10 mole $\%$, of praseodymium modified lead titanate ceramic.

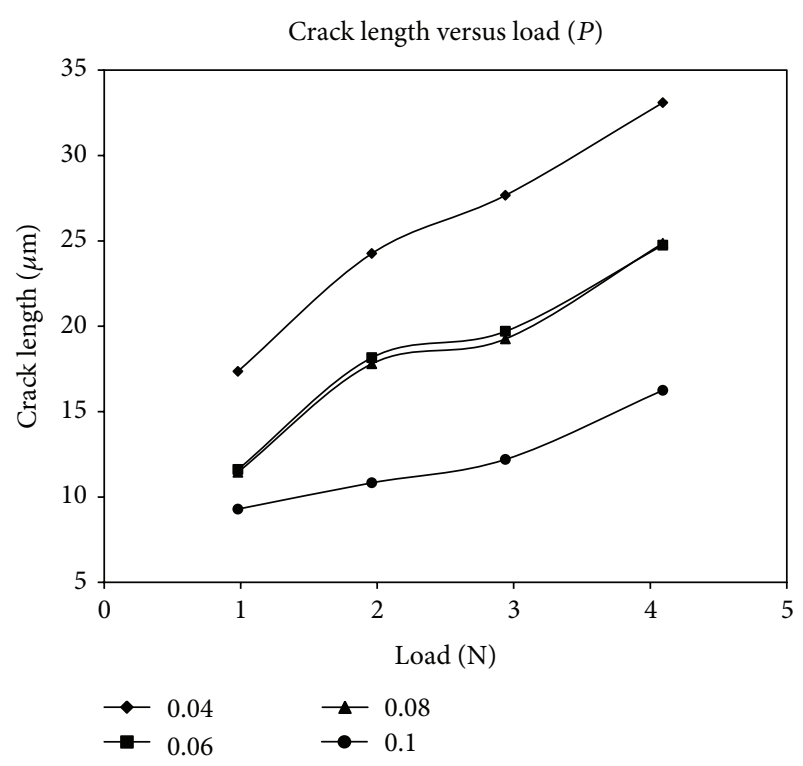

Figure 10: Crack length $(c)$ as a function of applied load $(P)$ for different compositions of PrPT.
3.3.2. Brittleness Index. Another important property that affects the mechanical behaviour of a material and reflects an idea about the fracture induced in a material without any appreciable deformation is expressed in terms of brittleness index $\left(B_{i}\right)$. From the value of fracture toughness, brittleness index $\left(B_{i}\right)$ can be calculated using the relation proposed by Niihara et al. [30]

$$
B_{i}=\frac{H_{v}}{K_{c}} .
$$

Dependence of brittleness index on load for different compositions of PrPT is shown in Figure 12. Brittleness index shows significant dependence on load in low load region for $10 \mathrm{~mol} \%$ of praseodymium. However, small decrease in $B_{i}$ in low load region with tendency to achieve saturation at higher loads is observed for other praseodymium modified composition.

\section{Conclusion}

The experimental density of praseodymium modified lead titanate with compositions $\mathrm{Pb}_{1-x} \mathrm{Pr}_{x} \mathrm{Ti}_{0.96} \mathrm{Fe}_{0.02} \mathrm{Mo}_{0.02} \mathrm{O}_{3}$ 


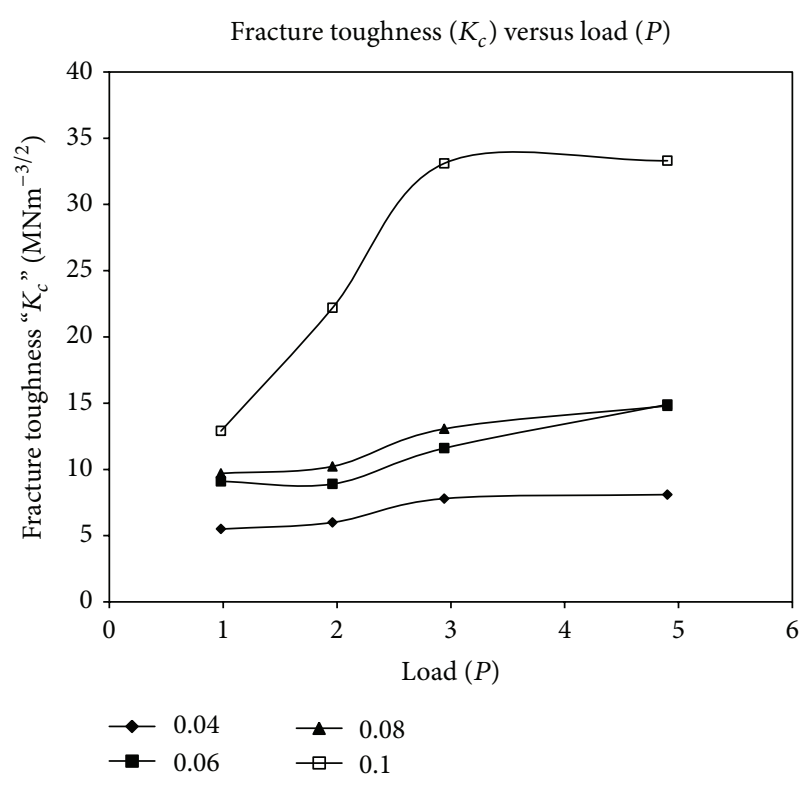

Figure 11: Fracture toughness $\left(K_{c}\right)$ as a function of applied load $(P)$ for four different compositions of PrPT.

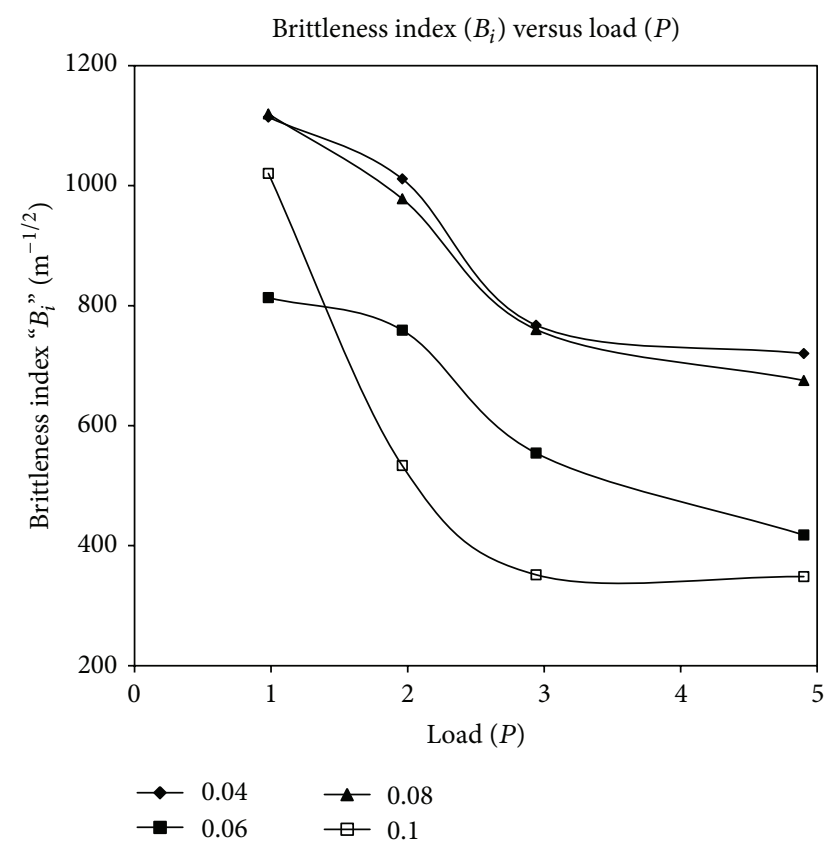

FIgURE 12: A curve showing brittleness index $\left(B_{i}\right)$ as a function of applied load $(P)$ for different compositions of PrPT.

where $x=4,6,8$, and 10 mole $\%$ increases, and crystal tetragonality $(c / a)$ decreases with the increase in Pr content as a result of which there is reduction in porosity. The variation of microhardness with applied load is nonlinear and fits well into the concept of Newtonian resistance pressure as proposed by Hays and Kendall's law. Application of this law gives load independent values of the microhardness for the 4, 6,8 , and 10 mole $\%$ of praseodymium modified lead titanate as $6018,6237,9704$, and $11566 \mathrm{MNm}^{-2}$, respectively. The load independent value of microhardness is found to increase linearly with the increase in praseodymium substitution due to the decrease in crystal tetragonality. Well-defined and measurable cracks are associated with the indentation impression at a load of $0.98 \mathrm{~N}$ and above. All the cracks are Palmqvist in nature. The crack length increases with the increase in load. However, at a constant load, crack length decreases with increase in praseodymium substitution. The values of fracture toughness $\left(K_{c}\right)$ and brittleness index $\left(B_{i}\right)$ strongly depend upon the applied load.

\section{Acknowledgment}

The authors are thankful to DRDO, New Delhi, India for providing grants under ER/IPR Grant in aid scheme.

\section{References}

[1] A. G. Evans and E. A. Charles, "Fracture toughness determination by indentation," Journal of the American Ceramic Society, vol. 59, no. 7-8, pp. 371-372, 1976.

[2] Y. Matsuo and H. Saski, "Effect of grain size on micro cracking in lead titanate ceramics," Journal of the American Ceramic Society, vol. 49, no. 4, pp. 229-230, 1966.

[3] T. Y. Tien and W. G. Carlson, "Effect of additive on properties of lead titanate," Journal of the American Ceramic Society, vol. 45, no. 12 , pp. 567-571, 1962.

[4] I. Ueda and S. Ikegarni, "Piezoelectric properties of modified $\mathrm{PbTiO}_{3}$ ceramics," Japanese Journal of Applied Physics, vol. 7, no. 3, pp. 236-242, 1968.

[5] V. Singh, K. K. Bamzai, S. Suri, and N. Nidhi, "Preparation, structural and electrical characteristics of praseodymium modified lead titanate," Ceramics International, vol. 37, no. 7, pp. 2655-2662, 2011.

[6] T. Takahashi, "Influence of samarium substitution on dielectric properties of barium titanate based ceramics," Ceramic Bulletin, vol. 69, pp. 691-695, 1990.

[7] P. Kumar, S. Singh, J. K. Juneja, C. Prakash, and K. K. Raina, "Influence of samarium substitution on dielectric properties of barium titanate based ceramics," Modern Physics Letters B, vol. 23, no. 28, pp. 3419-3425, 2009.

[8] C. Asaheron, C. Huse, G. Kuhn, and H. Neumann, "Microhardness of Sn-doped lnP," Crystal Research and Technology, vol. 24, pp. 33-35, 1989.

[9] K. Balakrishnan, B. Vengatesan, N. Kanniah, and P. Ramasamy, "Growth and microindentation studies of CulnSe $e_{2}$ single crystals," Journal of Materials Science Letters, vol. 9, no. 7, pp. 785787, 1990.

[10] K. K. Bamzai, P. N. Kotru, and B. M. Wanklyn, "Fracture mechanics, crack propagation and microhardness studies on flux grown $\mathrm{ErAlO}_{3}$ single crystals," Journal of Materials Science and Technology, vol. 16, no. 4, pp. 405-410, 2000.

[11] P. R. Dhar, K. Bamzai, and P. N. Kotru, "Deformation and microhardness studies on natural apophyllite crystals," Crystal Research and Technology, vol. 32, no. 4, pp. 537-544, 1997.

[12] J. Guille and M. Sieskind, "Microindentation studies on $\mathrm{BaFCl}$ single crystals," Journal of Materials Science, vol. 26, no. 4, pp. 899-903, 1991.

[13] J. Ricote, L. Pardo, and B. Jiménez, "Mechanical characterization of calcium-modified lead titanate ceramics by indentation 
methods," Journal of Materials Science, vol. 29, no. 12, pp. 32483254, 1994.

[14] H. Buckle, "Progress in microindentation hardness testing," International Materials Reviews, vol. 4, no. 1, pp. 49-100.

[15] J. R. Pandya, L. J. Bhagia, and A. J. Shah, "Microhardness of rhombohedral crystals: calcite and sodium nitrate," Bulletin of Materials Science, vol. 5, no. 1, pp. 79-82, 1983.

[16] C. A. Brookes, "The mechanical properties of cubic boron nitride-a perspective view," Institute of Physics Conference Series, vol. 75, pp. 207-220, 1986.

[17] F. Kick, Das Gesetz der proportionalen Widerstände und seine Anwendungen, Felix, Leipzig, Germany, 1885.

[18] J. B. Quinn and G. D. Quinn, "Indentation brittleness of ceramics: a fresh approach," Journal of Materials Science, vol. 32, no. 16, pp. 4331-4346, 1997.

[19] C. Hays and E. G. Kendall, "An analysis of Knoop microhardness," Metallography, vol. 6, no. 4, pp. 275-282, 1973.

[20] R. Tickoo, R. P. Tandon, N. C. Mehra, and P. N. Kotru, "Dielectric and ferroelectric properties of lanthanum modified lead titanate ceramics," Materials Science and Engineering B, vol. 94, no. 1, pp. 1-7, 2002.

[21] P. Duran, J. F. F. Lozano, F. Capel, and C. Moure, "Large electromechanical anisotropic modified lead titanate ceramics. Part 2: dielectric, piezoelectric and mechanical properties," Journal of Materials Science, vol. 24, no. 2, pp. 447-452, 1989.

[22] R. Tickoo, R. P. Tandon, V. K. Hans, K. K. Bamzai, and P. N. Kotru, "Electromechanical and piezoelectric studies of lanthanum modified lead titanate ceramics," Materials Science and Engineering B, vol. 100, no. 1, pp. 47-52, 2003.

[23] T. Yamamoto, H. Igarashi, and K. Okazaki, "Dielectric, electromechanical, optical, and mechanical properties of lanthanummodified lead titanate ceramics," Journal of the American Ceramic Society, vol. 66, no. 5, pp. 363-366, 1983.

[24] K. Okazaki, "Microstructure and properties of some electrooptic ceramics," Ferroelectrics, vol. 49, no. 1, pp. 141-150, 1983.

[25] J. R. Cahoon, W. H. Broughton, and A. R. Kutzak, "The determination of yield strength from hardness measurements," Metallurgical Transactions, vol. 2, no. 7, pp. 1979-1983, 1971.

[26] H. Ishikaa and N. Shinkai, "Critical load for median crack initiation in vickers indentation of glasses," Journal of the American Ceramic Society, vol. 65, no. 8, pp. C124-C127, 1980.

[27] B. R. Lawn and A. G. Evans, "A model for crack initiation in elastic/plastic indentation fields," Journal of Materials Science, vol. 12, no. 11, pp. 2195-2199, 1977.

[28] C. B. Ponton and R. D. Rawlings, "Dependence of the vickers indentation fracture toughness on the surface crack length," British Ceramic, vol. 88, no. 3, pp. 83-90, 1989.

[29] D. J. Bhat, "Elastic/plastic indentation damage in ceramics: the median/radial crack system," Journal of the American Ceramic Society C, vol. 64, no. 11, pp. C-165-C-166, 1981.

[30] K. Niihara, R. Morena, and D. P. H. Hasselman, "Evaluation of KIc of brittle solids by the indentation method with low crackto-indent ratios," Journal of Materials Science Letters, vol. 1, no. 1, pp. 13-16, 1982. 

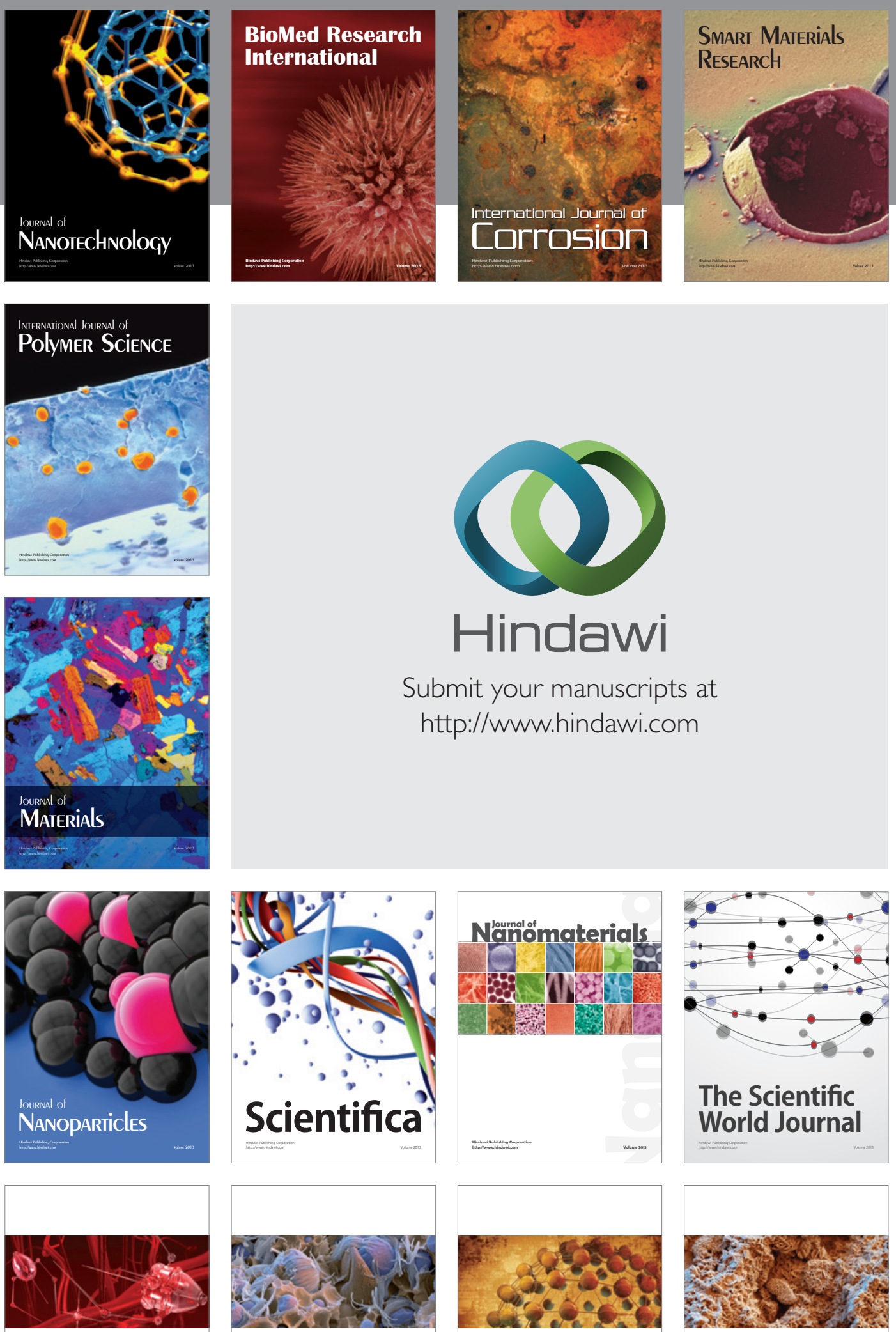

ISRN

Nanotechnology
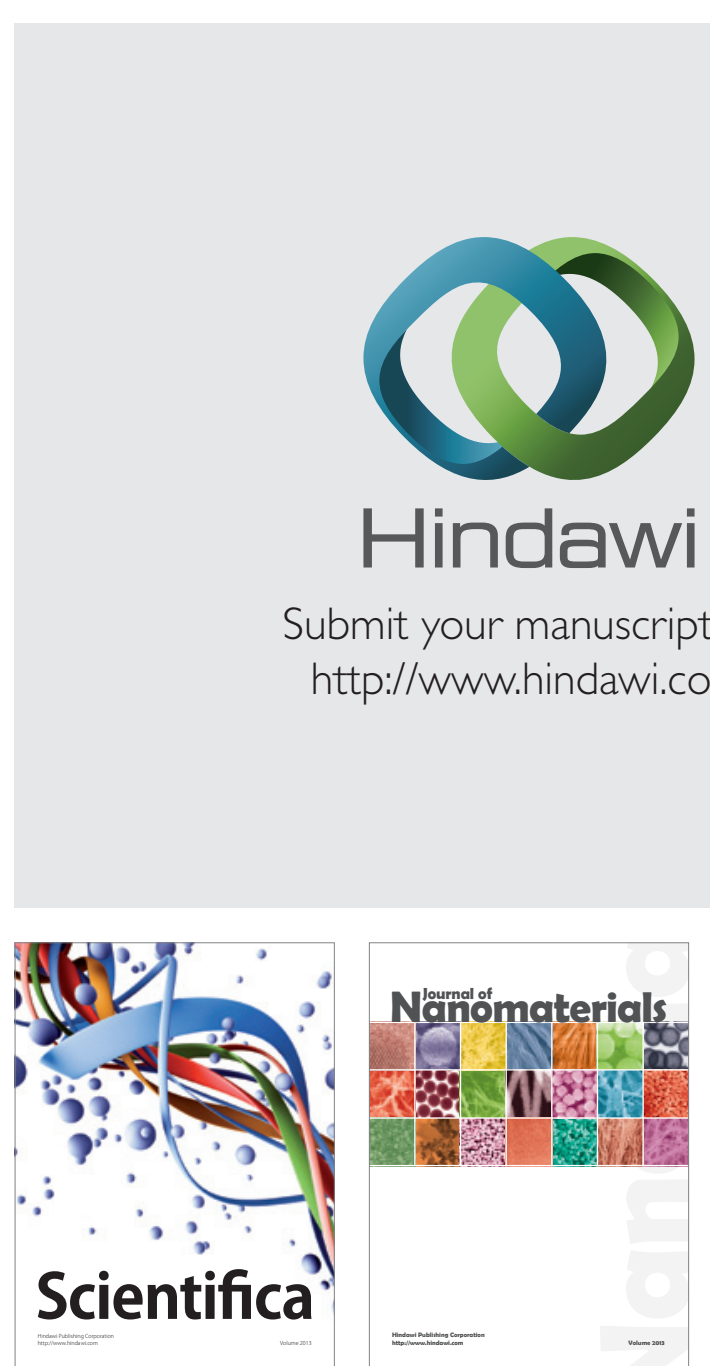

Submit your manuscripts at http://www.hindawi.com
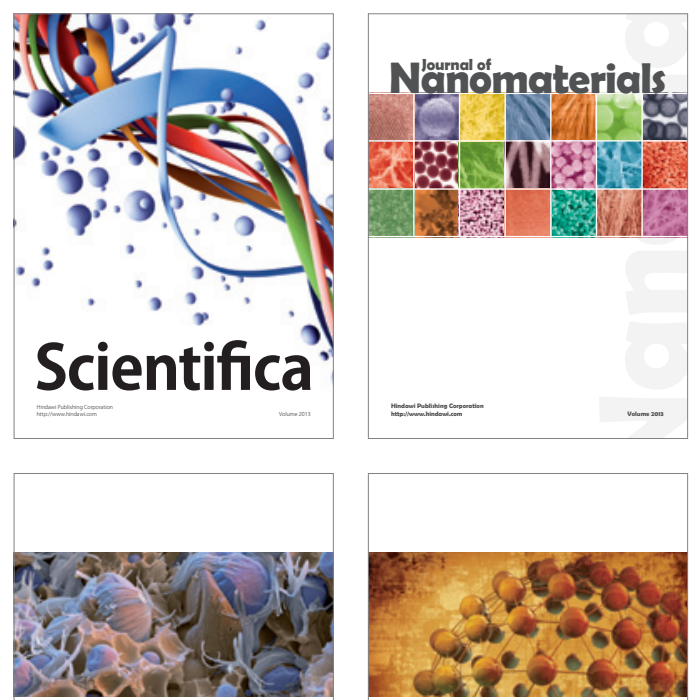

ISRN

Polymer Science

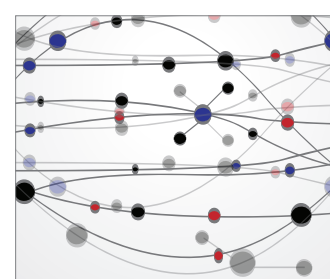

The Scientific World Journal

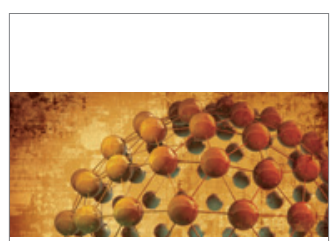

ISRN

Materials Science

\section{World Jounal}

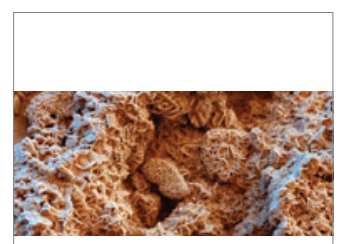

ISRN

Corrosion
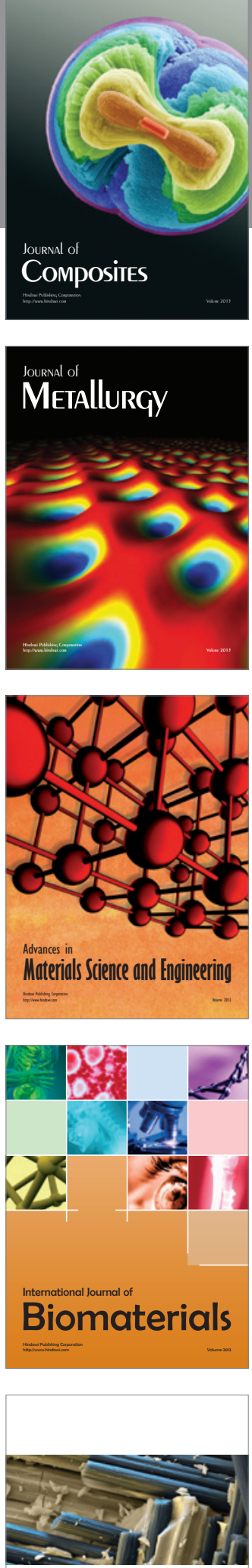

ISRN

Ceramics 